\title{
SOBRE O QUE TEMOS PESQUISADO? UMA ANÁLISE DOS OBJETOS DE ESTUDO DA PRODUÇÃO DISCENTE DO POSCOM/UFSM
}

\author{
What are we researching about? An analysis of study objects of student \\ production of POSCOM/UFSM
¿De qué estamos investigando? Análisis de los objetos de estudio de la producción estudiantil de POSCOM/UFSM

\begin{abstract}
Maria Ivete Trevisan Fossá Professora do Departamento de Comunicação e do Programa de Pós-Graduação em Comunicação da Universidade Federal de Santa Maria (UFSM). fossa@terra.com.br

Amanda Frick Martins Doutoranda do Programa de Pós-Graduação em Comunicação da Universidade Federal de Santa Maria (UFSM). rp.amandafrick@gmail.com

Kauane Andressa Müller Mestra em Comunicação pela Universidade Federal de Santa Maria (UFSM) kauaneamuller@gmail.com
\end{abstract}

\section{Resumo}

Este artigo investiga os objetos empíricos estudados na linha de Mídia e Estratégias Comunicacionais do Programa de Pós-Graduação em Comunicação da Universidade Federal de Santa Maria (UFSM). Para a análise foram consideradas dissertações e teses referentes à primeira década de produção efetiva do programa (2008-2017). A metodologia utilizada para categorizar os objetos foi a análise de conteúdo. Como resultado, os objetos foram agrupados em nove grandes categorias temáticas, sendo que a maior parte dos trabalhos aborda os objetos classificados como organizações de mídia $(40,7 \%)$ e, nas subcategorias, como jornais $(38,2 \%)$. Palavras-chave: Objetos de estudo. Comunicação Midiática. Poscom/UFSM.

\section{Resumen}

Este artículo investiga los objetos empíricos estudiados en la línea de investigación Medio y Estrategias de Comunicación, del Programa de Postgrado en Comunicación, de la Universidad Federal de Santa María (UFSM). Para el análisis, se consideraron las disertaciones y tesis referentes a su primera década de producción efectiva (2008-2017). La metodología utilizada para clasificar los objetos fue el análisis de contenido. Como resultado, los objetos se agruparon en nueve categorías temáticas principales, y la mayoría del trabajo se dirigió a objetos 
clasificados como organizaciones de medios $(40,7 \%)$ y, en las subcategorías, como periódicos $(38,2 \%)$.

Palabras clave: Objetos de estudio. Medios de comunicación. Poscom/UFSM.

\begin{abstract}
This article investigates the empirical objects studied in the line of research Media and Communication Strategies line of research of the Postgraduate Program in Communication at the Federal University of Santa Maria (UFSM). For the analysis, we considered the dissertations and theses of the program's first decade of effective production (2008-2017). The content analysis was the methodology used to categorize the objects. As a result, the objects were grouped in nine thematic categories, with most of the work addressing objects classified as media organizations (40.7\%), and, in the subcategories, as newspapers (38.2\%).
\end{abstract}

Keywords: Study objects. Media Communication. Poscom/UFSM.

\title{
1. Introdução
}

O Programa de Pós-Graduação em Comunicação (Poscom) da Universidade Federal de Santa Maria (UFSM), criado em 2006, é considerado conceito 5 pela Coordenação de Aperfeiçoamento de Pessoal de Nível Superior (CAPES) 2013, mantendo esse conceito desde então. O programa possui duas linhas de pesquisa, em que se dividem seus professores: Mídia e Identidades Contemporâneas e Mídia e Estratégias Comunicacionais. O Grupo de Pesquisa em Comunicação Institucional e Organizacional, responsável por esta pesquisa, localiza-se na segunda.

Sendo o primeiro programa de pós-graduação na área de comunicação localizado no interior de um estado do Sul do Brasil, o Poscom é um importante responsável pela formação de docentes e pesquisadores e pela manutenção da pesquisa em comunicação na região. A linha de pesquisa Mídia e Estratégias Comunicacionais, que existe desde a fundação do programa, produziu um total de 76 trabalhos nos dez anos iniciais de produção efetiva do programa (20082017), entre dissertações e teses. Percebemos então a necessidade da realização de um levantamento dos objetos mais estudados pela linha. Este trabalho faz parte de uma pesquisa mais abrangente, que engloba um inventário de todos os trabalhos produzidos ao longo de uma década de pesquisa na linha, buscando identificar aspectos de ordem teórica, metodológica e empírica nos trabalhos da linha de pesquisa.

Assim, o objetivo deste artigo é investigar os objetos empíricos estudados na linha de Mídia e Estratégias Comunicacionais do Programa de Pós-Graduação em Comunicação da UFSM. Para a análise foram consideradas as dissertações e teses dos primeiros dez anos de produção efetiva do programa. Os trabalhos inicialmente foram analisados pela pesquisa 
anteriormente citada. Em seguida, foi aplicada a análise de conteúdo nos 31 trabalhos que tinham como elemento central o conceito de "estratégia" nas discussões apresentadas, classificando as categorias de objetos empíricos abordados. Buscou-se ainda identificar os objetos de estudo mais investigados no programa por meio do agrupamento em categorias temáticas.

\section{Objetos de pesquisa em comunicação}

Neste artigo buscamos compreender quais objetos da comunicação estão sendo investigados no Poscom, com ênfase nos primeiros dez anos de produção efetiva do programa. Para isso, precisamos abarcar conceitos que nos auxiliem no entendimento do que é um objeto para a pesquisa em comunicação. Segundo Braga (2011), no final dos anos 90, as discussões sobre o objeto da comunicação estavam em plena luz na academia. Entretanto, essas definições estão menos cruciais atualmente, mas não deixam de serem pontos de divergência.

Para o autor, há duas tendências para os pesquisadores quando se faz necessário definir os objetos de pesquisa em comunicação. A primeira tendência é o entendimento de que tudo é comunicação. As relações interpessoais, as conversas informais e todas as trocas simbólicas que acontecem em nosso dia a dia podem ser investigadas como objetos de comunicação. Nesse entendimento, "a comunicação espalhando-se como objeto por todas as áreas, estando em todas as pautas, não está em nenhum lugar" (BRAGA, 2011, p. 65).

Dessa forma, corremos o risco da amplitude dos objetos, que pode ser um problema para situar a identidade acadêmica do campo comunicacional. A segunda tendência, definida por Braga (2011), é a setorização dos objetos nos quais o risco é diferente: se escolhe uma opção em detrimento de outra, ou seja, possibilidades de objetos de estudo terão que ser deixados de lado como forma de delimitar o campo de pesquisa.

Nas teses e dissertações que serão analisadas neste artigo os objetos apresentam enfoques nos meios de comunicação social. Isso se dá pelo processo de escolha do Poscom que, em sua criação, teve sua área de concentração delimitada como Comunicação Midiática. Dessa forma, conforme afirma Braga (2011, p. 66), o “objeto de comunicação não pode ser apreendido enquanto coisas nem temas, mas sim como um certo tipo de processo epistemicamente caracterizados por uma perspectiva comunicacional".

A perspectiva adotada pelo programa é o midiático, o que conforme veremos na análise dos trabalhos, reflete também nas escolhas dos objetos a serem analisados nas pesquisas. Conforme França (2016), as delimitações dos objetos da comunicação podem aparecer em duas 
dimensões distintas, mas que estão intimamente articuladas: os objetos empíricos e o objeto do conhecimento. No primeiro, temos "aquilo que se estuda" (FRANÇA, 2016. p.157), o que optamos por chamar neste artigo de corpus de pesquisa. É a empiria onde encontramos os conceitos e as teorias comunicacionais aplicadas. Como objeto de conhecimento a autora entende o olhar do pesquisador para a empiria e como enxergá-lo como comunicação.

Ainda sobre a empiria nas pesquisas, a autora pontua

[...] é igualmente necessário destacar que não existe pesquisa empírica (estudo das coisas do mundo) desvestida de pressupostos sobre o real: ao tratar de uma dada empiria, o fazemos sob certa perspectiva, e é a criação de objetos de estudo que categoriza e trata de uma determinada maneira - e não de outra - o mundo empírico. Ao começarmos a estudar objetos e práticas enquanto comunicação, criamos o objeto comunicacional (FRANÇA, 2016. p. 158)

Sendo assim, são as escolhas durante o processo de análise que determinam o olhar sobre o objeto e o fazem comunicacional. A partir das escolhas que os pesquisadores fazem no recorte do corpus de análise, do período de análise e de como aplicar a metodologia ao empírico é que surge o objeto comunicacional.

Tavares (2008) acrescenta que este olhar que busca construir sobre os objetos da comunicação também percebe e reconstrói os fios invisíveis que engendram a realidade. Assim, a pesquisa em comunicação é vista como constitutiva da realidade social. Nesse sentido França (2016) corrobora em dizer que o campo da comunicação não tem um conteúdo fixo nem um lugar circunscrito. Para a autora, a comunicação se estabelece "no entre".

Sabemos que, se os objetos dependem do olhar do pesquisador para terem sentido na pesquisa em comunicação, o que não é visto nesse processo acaba por se tornar uma lacuna no campo. Sobre isso, Tavares (2008, p. 06) apresenta uma definição da noção de "pertinência lacunar". Para o autor todos os estudos são pertinentes, mas, da mesma forma, apresentam lacunas, tanto referentes aos objetos de comunicação quanto ao campo de pesquisa.

Entenderemos agora um pouco mais sobre a comunicação midiática, área de concentração do Poscom. Com isso, conseguiremos interpretar a ambiência teórica dos objetos que serão analisados das teses e dissertações do programa.

\section{A pesquisa em comunicação midiática}

Assim como França (2016), para Muniz Sodré, em entrevista publicada pela revista Parágrafo, afirma que o estudo da comunicação - a ciência do comum - tem como especificidade a sua perspectiva (GROHMANN, 2015), ou seja, o olhar que o pesquisador 
atribui. Dessa forma, o estudo da mídia não necessariamente seria central para o campo, embora ele seja, de fato, importante. Mas este estudioso entende a comunicação como o vínculo que une a sociedade. Assim, pode-se dizer que os produtos midiáticos não são o objeto único do estudo em comunicação.

O Programa de Pós-Graduação em Comunicação da Universidade Federal de Santa Maria tem como área de concentração a Comunicação Midiática. Em sua apresentação, afirma que "ocupa-se prioritariamente de estudar as formas através das quais a comunicação midiática incide na associação, configuração e solidificação das relações sociais no tempo e no espaço" (UFSM, 2019). Sem que apresente uma definição explícita do que se refere ao abordar a comunicação midiática, o programa entende estudar a incidência da "ação midiática" em esferas diversas.

O que chamamos de comunicação midiática é aqui entendido como a ação exercida pelas mídias, em função delas ou por meio de suas lógicas, em diferentes suportes comunicativos. No contexto da midiatização, ao mesmo tempo que a mídia se configura como uma instituição em si mesma, e cuja existência as outras instituições precisam se adaptar, ela interfere nas atividades de outras instituições, num processo de via dupla (HJARVARD, 2012). Nesse sentido, há impacto social do e no processo comunicativo, já que a sociedade do nosso tempo sofre os atravessamentos da ambiência midiática, ainda que em níveis diferentes de acordo com fatores de ordem econômica, política, histórica.

Dessa forma, a proposta do Poscom em sua área de concentração enfatiza justamente a compreensão ampla do processo midiático. Faz isso dando conta da atividade própria das organizações, empresas e agrupamentos de mídia, estritamente. E, ao mesmo tempo, abordando a (re)organização de qualquer outro tipo de empresa, organização e atividade que, mesmo não tendo a circulação midiática como atividade-fim, se insere em sua ambiência, faz uso dos processos midiáticos em sua rotina e é atravessada pela lógica da mídia.

Para Milton Santos (1994, p.49), “a instantaneidade da informação globalizada aproxima os lugares, torna possível uma tomada de conhecimento imediata de acontecimentos simultâneos e cria entre lugares e acontecimentos uma relação unitária na escala do mundo". O nosso tempo é, portanto, marcado pelos processos de comunicação instantânea e midiática, ainda que não apenas por eles. Para o geógrafo, o meio técnico, científico e informacional incluído aí o que chamamos de comunicação midiática - está presente em toda a parte, ainda que não igualmente. Daí decorre a importância dessa discussão a partir de diferentes olhares, o 
que se demonstra na variedade de objetos teóricos e empíricos estudados na pesquisa em comunicação.

Nesse contexto, a circulação de informação adquire características próprias, marcadas também pela sua importância econômica. Ao longo do século XX, consolidou-se um modelo de jornalismo e de comunicação em que empresas que tinham essas atividades como fim se estabeleceram a partir de negócios lucrativos, ainda que esse modelo encontre dificuldades de se manter rentável na atualidade. Por outro lado, desde o advento da internet comercial, cresce a importância de outros tipos de conglomerados de mídia e informação, como as gigantes de tecnologia Google e Facebook, que crescem sem regulamentação e hoje são um importante setor do capitalismo financeiro. Dessa forma, a mídia e, mais do que isso, a comunicação midiática e seus agentes, devido ao seu poder de mercado $^{1}$, atua em nível cultural, econômico e político.

Além disso, dizer que a mídia e sua lógica interferem nos diversos espaços sociais significa compreender que as demais organizações e instituições da sociedade atuam também conforme e a partir de lógicas midiáticas. Ou seja,

Uma parte significativa da influência que a mídia exerce decorre do fato de que ela se tornou uma parte integral do funcionamento de outras instituições, embora também tenha alcançado um grau de autodeterminação e autoridade que obriga essas instituições, em maior ou menor grau, a submeterem-se a sua lógica." (HJARVARD, 2012, p.54)

Assim, ao enfatizar a comunicação midiática, o Poscom busca abranger essas questões de maneira ampla. Da mesma forma, a linha de pesquisa Mídia e Estratégias Comunicacionais busca abranger a relação da mídia com a sociedade e as demais instituições impactadas por ela. De acordo com a página do programa, a linha "refere-se às estratégias que agem como promotoras da articulação e de organização entre a esfera midiática e os demais campos sociais" (UFSM, 2019). Pode-se compreender, portanto, que esta linha busca entender os processos e, dentro deles, as estratégias ${ }^{2}$ pelas quais a relação entre mídia e sociedade se articula.

\footnotetext{
${ }^{1} \mathrm{O}$ ranking produzido anualmente pela revista Forbes apontou em 2018, o empresário estadunidense Mark Zuckerberg fundador do Facebook, como a oitava pessoa mais rica do mundo, com uma fortuna estimada em $\$ 62.3$ bilhões.

${ }^{2}$ Neste artigo optamos por não aprofundar as definições de estratégias de comunicação, visto que outros artigos da mesma pesquisa irão dar conta deste tema.
} 


\section{Os objetos que preocupam o Poscom}

Os resultados aqui apresentados tiveram como base um trabalho de maior fôlego, desenvolvido pelo Grupo de Pesquisa em Comunicação Institucional e Organizacional da UFSM. O objetivo da investigação desenvolvida e apresentada parcialmente nesse trabalho foi problematizar as concepções teóricas acerca das estratégias de comunicação na busca de mapear as diversas conceituações, intervir e propor compreensões a elas.

Para isso, buscamos realizar uma investigação nas dissertações e teses produzidas ao longo de uma década na linha de pesquisa Mídia e Estratégias Comunicacionais do Poscom. Para o corpus, um mapeamento inicial identificou que 31 dos 76 trabalhos defendidos entre os anos de 2008 e 2017 apresentavam o conceito de "estratégia" como elemento central nas discussões. A partir disso, foi elaborado um formulário na plataforma Excel, produzido e discutido coletivamente nos encontros do grupo de pesquisa. Ele permitiu, entre outras coisas, identificar os objetos estudados na linha Mídia e Estratégias Comunicacionais.

Para a investigação proposta neste artigo, nos inspiramos na análise de conteúdo apresentada por Bardin (2011). Utilizamos da análise temática para iniciarmos a classificação dos objetos das teses e dissertações, uma vez que "o tema é a unidade de significação que se liberta naturalmente de um texto analisado [...] e pode ser recortado em ideias constituintes, em enunciados e em proposições portadores de significações isoláveis” (BARDIN, 2011, p.135).

Das 31 dissertações e teses selecionadas para a análise, encontramos trabalhos que analisaram mais de um objeto. Por exemplo, uma dissertação defendida em 2008 por Salbego, cuja análise de VTs publicitários se dá em seis organizações diferentes: Kaiser, Antártica, Sol, Brahma, Pepsi e Coca-Cola. Na classificação temática proposta neste trabalho, cada empresa destas é considerada um objeto diferente, auxiliando na compreensão da totalidade quantitativa maior do que o número total de trabalhos. Tivemos então um total de 113 objetos de pesquisa, que foram posteriormente organizados em grandes categorias para melhor interpretação dos dados.

A primeira tematização apresenta os segmentos encontrados nos objetos de pesquisa analisados. Chegou-se a um total de nove grandes categorias temáticas. São elas: Acontecimento; Campanha Eleitoral; Empresas Privadas; Grupo Musical; Organizações Religiosas; Organizações de Mídia; Organizações do Terceiro Setor; Organizações Públicas e Instituições de ensino. 
PROGRAMA DE PÓS-GRADUAÇÃO EM COMUNICAÇÃO DA UNIVERSIDADE FEDERAL DE SANTA MARIA

Quadro 1 - Tematização dos objetos de pesquisa

\begin{tabular}{|c|c|c|c|c|}
\hline \multirow{2}{*}{ Categorias } & \multirow{2}{*}{ Componentes } & \multirow{2}{*}{ Exemplos } & \multicolumn{2}{|c|}{ Frequência } \\
\hline & & & Unidade & $\%$ \\
\hline Acontecimento & $\begin{array}{l}\text { Eventos, ações e mobilizações } \\
\text { esporádicas ou não, que foram } \\
\text { pesquisados como objetos de } \\
\text { comunicação. }\end{array}$ & $\begin{array}{l}\text { Desfile de } 7 \text { de } \\
\text { Setembro }\end{array}$ & 02 & 1,7 \\
\hline Campanha Eleitoral & $\begin{array}{l}\text { Campanhas para cargos } \\
\text { públicos, sendo de origem } \\
\text { municipais, estaduais ou } \\
\text { federais. }\end{array}$ & $\begin{array}{l}\text { Campanha } \\
\text { Yeda Crusius } \\
\text { para o governo } \\
\text { do estado do } \\
\text { RS. }\end{array}$ & 02 & 1,7 \\
\hline Empresas Privadas & $\begin{array}{l}\text { Organizações privadas que } \\
\text { foram alvo de algum tipo de } \\
\text { análise. }\end{array}$ & $\begin{array}{l}\text { Havaianas; } \\
\text { Natura; Skol }\end{array}$ & 30 & 26,5 \\
\hline Grupo Musical & $\begin{array}{l}\text { Grupo musical ou artista da } \\
\text { música que serviu para análise } \\
\text { de pesquisa. }\end{array}$ & $\begin{array}{l}\text { Dream Team do } \\
\text { Passinho }\end{array}$ & 1 & 0,8 \\
\hline $\begin{array}{c}\text { Organizações } \\
\text { Religiosas }\end{array}$ & $\begin{array}{l}\text { Igrejas, entidades ou grupos } \\
\text { religiosos que foram } \\
\text { analisados. }\end{array}$ & $\begin{array}{l}\text { Igreja } \\
\text { Neopentecostal }\end{array}$ & 3 & 2,6 \\
\hline Organizações de Mídia & $\begin{array}{l}\text { Empresas que oferecem o } \\
\text { serviço de mídia, sendo } \\
\text { considerada aqui jornal, TV, } \\
\text { revista, site ou grupos de } \\
\text { mídia. Essas organizações } \\
\text { podem ser privadas, públicas } \\
\text { ou comunitárias. }\end{array}$ & $\begin{array}{l}\text { Revista Época; } \\
\text { Grupo RBS; } \\
\text { Folha de } \\
\text { S.Paulo }\end{array}$ & 46 & 40,7 \\
\hline $\begin{array}{c}\text { Organizações do } \\
\text { Terceiro Setor }\end{array}$ & $\begin{array}{l}\text { Agrupa-se ONGs, OSCIPs, } \\
\text { Entidades sem fins-lucrativos e } \\
\text { projetos sociais. }\end{array}$ & Greenpeace & 3 & 2,6 \\
\hline Organizações Públicas & $\begin{array}{l}\text { Órgão que fazem parte dos } \\
\text { governos municipais, } \\
\text { estaduais ou federais e } \\
\text { empresas estatais. }\end{array}$ & $\begin{array}{l}\text { Câmara } \\
\text { Legislativa de } \\
\text { Municípios, } \\
\text { Petrobrás }\end{array}$ & 23 & 20,6 \\
\hline Instituições de ensino & $\begin{array}{l}\text { Entende-se aqui tanto } \\
\text { universidades públicas quanto } \\
\text { universidades particulares. }\end{array}$ & UFSM, UNISC & 3 & 2,6 \\
\hline
\end{tabular}

Fonte: Elaborado pelos autores 
A categoria Grupo Musical teve apenas uma incidência dentre os trabalhos analisados. As categorias Acontecimento e Campanha Eleitoral representam dois trabalhos cada na categoria dos objetos. As três categorias citadas representam menos de $2 \%$ da amostragem do corpus. Apesar disso, é um importante indício do que pode ser mais explorado como objeto empírico na área de comunicação. Chama-se atenção para as campanhas eleitorais, que são grandes oportunidades de análise de estratégias comunicacionais, uma vez que são parte responsável pela manutenção de um sistema democrático.

As categorias de Organizações Religiosas, Organizações do Terceiro Setor e Universidades Públicas e Privadas têm três representantes cada. Com um percentual de 2,6\% cada categoria, elas indicam um interesse de investigação ainda reduzido por parte dos pesquisadores da linha Mídia e Estratégias Comunicacionais.

A categoria de Organizações Públicas representa 20,3\% do corpus analisado, sendo o terceiro maior tema. Os objetos desta categoria trazem, em sua maioria, o debate da comunicação pública nas alçadas municipal, estadual ou federal, representando um importante tema para a área.

A segunda maior categoria representa 26,5\% do corpus, sendo Empresas Privadas. Englobam as empresas que visam ao lucro e não têm como atividade fim negócios de mídia. É uma categoria bem expressiva para as estratégias comunicacionais, que pode significar uma visibilidade das estratégias de mercado utilizadas por estas empresas. Além disso, nota-se uma preocupação da academia com esse tipo de organizações, aparentando uma inclinação nas pesquisas para $\mathrm{o} 2^{\circ}$ setor.

A categoria mais representativa é a de Organizações de Mídia, representando 40,7\% do corpus. Essa categoria engloba os diversos tipos de mídia, sendo elas site, jornal, rádio ou TV. No seguir da análise iremos aprofundar a compreensão desta categoria, uma vez que além de ser a mais expressiva do corpus analisado, é a que apresenta uma relação mais direta com o programa de pós-graduação.

O Poscom, que visa compreender a comunicação midiática e os processos que perpassam de alguma forma esfera midiática, tem a maioria de seus objetos de pesquisa as organizações de mídia por este recorte apresentado. É possível inferir, assim, que há, no programa, uma grande preocupação em estudar as organizações midiáticas. É preciso lembrar que a ideia de mídia, como demonstra Hjarvard (2012), não se restringe apenas às organizações em si. Dessa forma, uma pesquisa que tenha como objeto o governo e suas propagandas 
exibidas na televisão, por exemplo, também abrange o que se entende como mídia. Da mesma forma, Facebook é a organização midiática, o meio é a internet.

Entende-se que os textos apresentados nas disciplinas do programa e orientação dos professores de mestrado e doutorado tem influência direta nos resultados apresentados. É importante lembrar, no entanto, que os trabalhos aqui analisados não representam o todo das dissertações e teses desenvolvidas no Poscom, mas apenas aqueles da linha de pesquisa Mídia e Estratégias Comunicacionais que apresentaram o conceito de "estratégia" como elemento central nas discussões.

Abaixo, seguiremos a análise da categoria de Organizações de Mídia com o intuito de compreender o que é analisado nestas organizações. Se o que é estudado nas teses e dissertações são os processos ou os produtos, e também quais destas organizações estão despertando maior interesse para as pesquisas. A tematização dos objetos que são organizações de mídia está disposta no quadro a seguir.

Quadro 2 - Tematização dos objetos organizações de mídia

\begin{tabular}{|c|c|c|c|c|}
\hline \multirow{2}{*}{ Categorias } & \multirow{2}{*}{ Componentes } & \multirow{2}{*}{ Exemplos } & \multicolumn{2}{|c|}{ Frequência } \\
\hline & & & Unidade & $\%$ \\
\hline Grupo de Mídia & $\begin{array}{l}\text { Conglomerados de empresas } \\
\text { que formam grupos de mídia }\end{array}$ & Grupo RBS & 1 & 2,1 \\
\hline Jornal & $\begin{array}{l}\text { Considerados aqui empresas } \\
\text { jornalísticas que se intitulam } \\
\text { como Jornal tanto impressos } \\
\text { quanto no seu formato online. }\end{array}$ & $\begin{array}{l}\text { Zero Hora, Folha } \\
\text { de S. Paulo, O } \\
\text { Estado de } \\
\text { S.Paulo }\end{array}$ & 18 & 38,2 \\
\hline TV & Empresas de mídia televisão & $\begin{array}{l}\text { TV Globo } \\
\text { TV Record }\end{array}$ & 12 & 25,5 \\
\hline Rádio & $\begin{array}{l}\text { Empresas de mídia rádio, } \\
\text { tanto privadas quanto } \\
\text { públicas ou comunitárias. }\end{array}$ & $\begin{array}{l}\text { Rádio CBN, } \\
\text { Rádiocom FM }\end{array}$ & 6 & 12,7 \\
\hline Site & $\begin{array}{l}\text { Empresas especializadas em } \\
\text { portais de notícia ou } \\
\text { entretenimento. }\end{array}$ & Charges.com & 2 & 4,2 \\
\hline Revista & $\begin{array}{l}\text { Empresas de mídia revista, } \\
\text { tanto impressas quanto de } \\
\text { material online. }\end{array}$ & $\begin{array}{l}\text { Revista Veja, } \\
\text { Exame }\end{array}$ & 8 & 17 \\
\hline
\end{tabular}

Fonte: Elaborado pelos autores 
Entendemos que se faz necessário observar mais atentamente a categoria organizações de mídia, que representa $46 \%$ do todo de objetos estudados pelos trabalhos em análise neste artigo. Jornal foi a subcategoria de objeto com maior incidência no Poscom: foram 18 vezes, representando $38,2 \%$ do total de trabalhos observados. É importante destacar que, para essa classificação, foram considerados como jornais todas as empresas jornalísticas que assim se intitularam, sem distinção entre os formatos impresso e digital.

As empresas de mídia televisiva foram a segunda subcategoria de objeto mais analisada pelos trabalhos que abordavam a noção de "estratégias". Elas foram objeto de pesquisa 12 vezes, ou seja, 25,5\% do total. Em seguida, estiveram as revistas, tanto impressas, quanto digitais, que representam $17 \%$ dos objetos de análise dos trabalhos investigados, ou seja, apareceram oito vezes. As rádios, por sua vez, sejam elas públicas, privadas ou comunitárias, foram observadas seis vezes, o que representa $12,7 \%$ dos objetos. Os sites, considerados como as empresas especializadas em portais de notícia ou entretenimento, e os conglomerados de empresas que formam grupos de mídia foram os menos investigados, aparecendo apenas dois $(4,2 \%)$ e um $(2,1 \%)$, respectivamente.

A descrição das categorias e subcategorias analisadas pelas dissertações e teses em estudo neste trabalho ajuda a identificar quais os objetos mais trabalhados pela linha de Mídia e Estratégias Comunicacionais. Isso é importante porque nos ajuda a ampliar o olhar e compreender como o Poscom vem se dedicando a diferentes objetos e quais recebem menos atenção. Esse é o caso, por exemplo, dos conglomerados de mídia, dos sites de notícias e entretenimento - que não se apresentam como jornal ou revista - e, até mesmo, das rádios.

Apresentamos no gráfico 01 as empresas de mídia citadas como objetos de pesquisa. $\mathrm{O}$ jornal Zero Hora é o mais citado, aparecendo em sete trabalhos analisados do programa. O segundo foi o jornal Folha de São Paulo, estudado em quatro trabalhos, junto com a TV Globo. As revistas Veja e Exame aparecem ambas em três trabalhos do programa.

Chamamos atenção também para as empresas locais e de menores proporções que as empresas de mídia nacional, como é o caso da TV Santa Maria - TV comunitária da cidade de Santa Maria; Jornal Diário de Santa Maria e o extinto Jornal A Razão, ambos jornais da cidade que serviram como objetos de investigação.

É necessário destacar a importância da investigação das mídias locais, por este ser um programa de pós-graduação em uma universidade localizada no interior do estado do Rio Grande do Sul. O regionalismo nesse caso aparece nas escolhas destas empresas para análise e 
proporciona uma perspectiva crítica ao que acontece geograficamente próximo ao Poscom, como forma de desenvolver a comunicação midiática em realidade próxima aos pesquisadores.

Gráfico 1: Empresas citadas como organizações de mídia

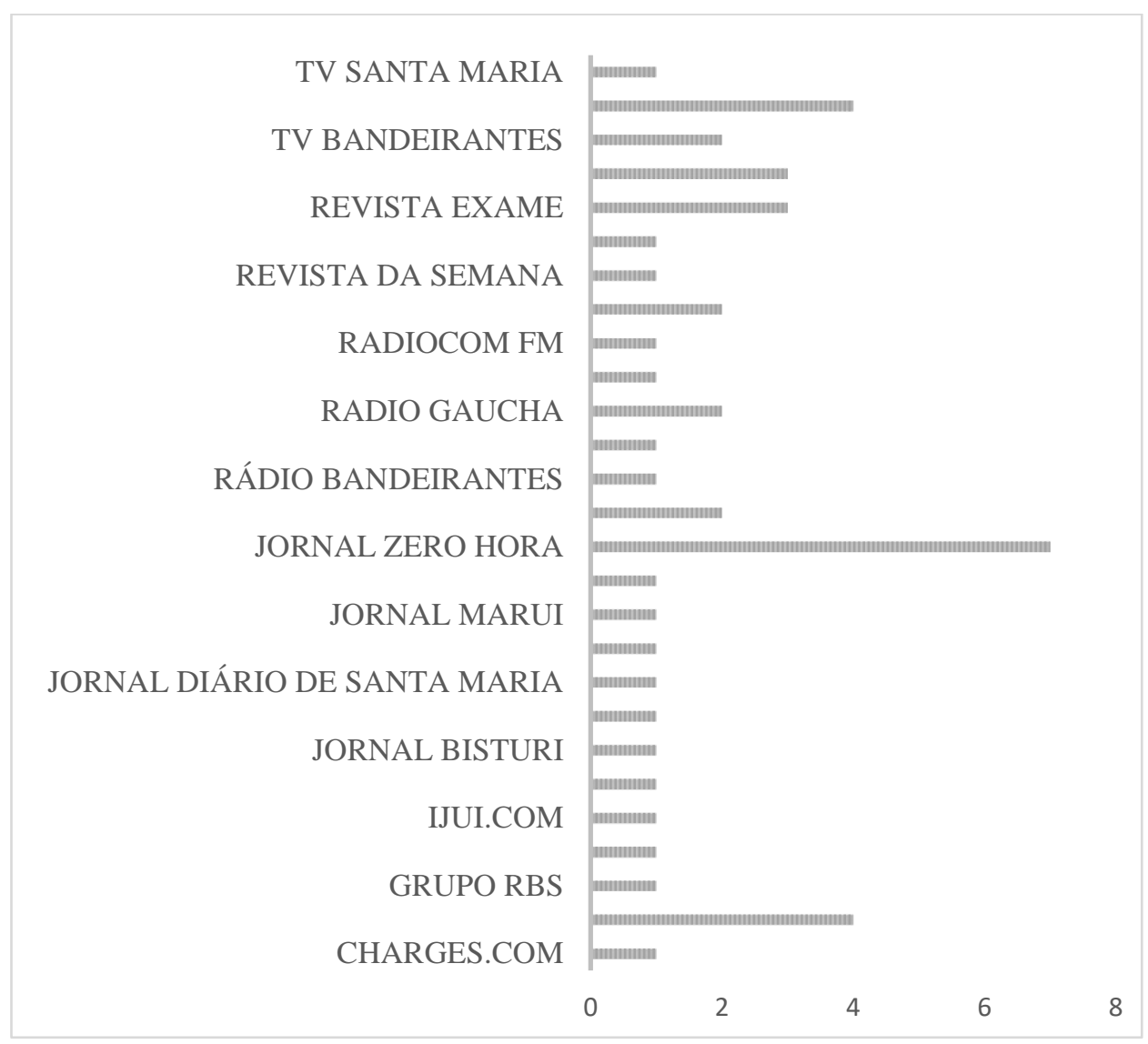

Fonte: Elaborado pelos autores

A partir da compreensão dos pontos teóricos trazidos neste artigo, de que a comunicação é uma perspectiva, entendemos ser importante ainda observar qual os questionamentos que formam estes objetos empíricos. Para isso, observamos os problemas de pesquisa apresentados pelos autores dos trabalhos.

Evidenciaremos algumas questões que foram feitas, concentrando-nos naqueles que tiveram como objeto empírico a organização de mídia Zero Hora, a qual apareceu mais vezes como objeto das dissertações e teses no corpus analisado.

Dos sete trabalhos que investigaram o jornal Zero Hora, um não apresentou problema de pesquisa (GROSSMANN, 2008). O trabalho de Belochio (2009, p.13) tem a seguinte questão como problema de pesquisa: “As seções colaborativas representam a des-reterritorialização no jornalismo digital?". Ele investiga 96 capas de zerohora.com, 68 publicações na seção Leitor-Repórter e uma entrevista com uma editora de Zero Hora. O 
trabalho defendido por Casaroli (2009, p.9), por sua vez, afirma que sua problemática é "compreender como uma organização se posiciona para lograr uma imagem positiva de si e obter a confiança de seus públicos, em termos de contrato de leitura.”. Para isso, analisou 39 colunas de "Carta do editor" de Zero Hora.

Já dissertação apresentada por Carvalho (2011) teve como problema “que estratégias de legitimação institucional emergem no conteúdo das mensagens postadas pelo jornal Zero Hora no Twitter?". O trabalho investigou a redação de Zero Hora. A mesma autora em sua tese também investigou o jornal, porém agora com outra perspectiva. Guiada pela problemática “de que forma, e por meio de que estratégias semiolinguísticas, a instância de produção do jornalismo desenvolve o contrato de informação no dispositivo de mídia social digital que se configura no Facebook?”, Carvalho (2015) se debruçou sobre outra plataforma digital para analisar o objeto.

A tese de Pérsigo (2015), que investigou notícias publicadas por Zero Hora, teve como pergunta “como o jornalismo público se apresenta nas práticas jornalísticas de ZH?”. E a dissertação de Casagrande (2014) objetivou responder a seguinte problemática: "que estratégias discursivas são elaboradas por enunciadores da Folha de São Paulo e Zero Hora para a produção de efeitos de sentido que afirmam e manuseiam valores humanos e sociais sobre a temática da violência no futebol".

$\mathrm{O}$ que percebemos a partir das diferentes questões de pesquisa apresentada para o Jornal Zero Hora é que se faz necessário olhar além do objeto empírico pesquisado, já que compreender o olhar que o pesquisador dá para o objeto a partir do seu questionamento é fundamental para entendermos o que está sendo pesquisado pelo campo comunicacional. Sobre o exemplo tomado acima, o Jornal Zero Hora é visto desde objeto para constatação do jornalismo público até como uma organização que posiciona sua imagem organização nas plataformas digitais como os sites Twitter e Facebook.

Além disso, podemos perceber que cada questionamento põe luz sobre uma parte do jornal - como as colunas de opinião por exemplo - ou para o todo da organização através de metodologias distintas, como a observação não-participante ou entrevistas com cargos de direção.

Entendemos, assim, que os objetos são construídos pelo olhar de cada pesquisador e pelo caminho teórico-metodológico, escolhido a cada seção da pesquisa. Portanto, cada objeto pode ser pesquisado inúmeras vezes sob o olhar comunicacional e, mesmo assim, apresentar 
nuances que ainda foram pesquisados e que podem ser como lacunas em nosso campo acadêmico.

\section{Considerações finais}

Este artigo teve como objetivo investigar os objetos de pesquisa analisados ao longo de uma década na linha de pesquisa Mídia e Estratégias Comunicacionais. Para isso, por meio da análise de conteúdo, examinamos os objetos empíricos aos quais os mestrandos e doutorandos do Poscom lançaram seus olhares. Além disso, foi dedicada atenção às perguntas que eles fizeram, a partir da observação dos problemas de pesquisa apresentados pelas dissertações e teses que compunham nosso corpus.

O principal resultado desta pesquisa demonstra que os trabalhos produzidos no Poscom tiveram como foco, em sua maioria, a pesquisa sobre as empresas e organizações cuja atividadefim é a comunicação. Assim, a linha de pesquisa parece dedicar-se especialmente à análise dos meios de comunicação de massa. Entendemos que isso se deve, em parte, à área de concentração do programa, que é a Comunicação Midiática, que dá ênfase às diversas compreensões da ideia de mídia. Inferimos haver ainda um direcionamento das disciplinas ofertadas e do trabalho dos professores do programa nesse sentido.

É preciso dizer, no entanto, que mesmo os trabalhos que não têm como objeto um meio de comunicação são coerentes com a proposta do programa, já que há uma lógica da mídia que perpassa e é perpassada pelas diversas outras instituições (HJARVARD, 2012). Assim, a comunicação midiática pode representar ao mesmo tempo a ação exercida pelas mídias, em função delas ou por meio de suas lógicas.

O que determina, portanto, e diferencia a pesquisa em Comunicação da pesquisa em outros campos do conhecimento é a sua perspectiva sobre o objeto. Assim, o olhar comunicacional atribui sentidos à empiria, atuando na construção de um objeto mais amplo, que incorpora também um questionamento - representado pelo problema de pesquisa - e objetivos de investigação.

Estendendo a reflexão sobre o que consideramos organizações de mídia, categoria mais representativa daquelas encontradas em nossa análise, identificamos como principais objetos de pesquisa dos trabalhos analisados os jornais. Essa subcategoria incluiu todas as empresas jornalísticas apontadas como objeto das dissertações e teses que se intitulam como Jornal, sejam 
impressos ou digitais. Foram 18 incidências. Em seguida, vieram as empresas de televisão (12) e revistas (8).

Um ponto importante a ser destacado é o reduzido número de investigações sobre acontecimentos, campanhas eleitorais, grupos musicais, organizações do terceiro setor e instituições de ensino. Isso demonstra que há uma gama de pesquisas possíveis a serem realizadas nesses espaços, que poderiam receber maior atenção. Isso não significa que a ênfase em outros objetos, como as organizações de mídia e as empresas privadas, tenham esgotado as possibilidades de análise. Uma vez que, conforme vimos no artigo, os diferentes olhares para cada objeto empírico tomam um caminho de pesquisa diferente a partir das escolhas teóricometodológicas e do questionamento do pesquisador. Isso reafirma o campo de pesquisa em comunicação como necessário e apresentando lacunas para futuras investigações, já que as teorias e os objetos se encontram em constante movimento em nossa sociedade.

\section{Referências}

BARDIN, Laurence. Análise de Conteúdo. São Paulo: Edições 70, 2011.

BELOCHIO, Vivian de Carvalho. Jornalismo colaborativo em redes digitais: estratégia comunicacional no ciberespaço o caso de Zero Hora.com. 2009. 215p. Dissertação (Mestrado em Comunicação) - Universidade Federal de Santa Maria, Santa Maria, 2009.

BRAGA, José Luiz. Constituição do Campo da Comunicação. Verso e Reverso, v.25, n.58, janeiro-abril 2011.p. 62-77. Disponível em:

http://revistas.unisinos.br/index.php/versoereverso/article/view/924. Acesso em 12 dez. 2019.

CARVALHO, Luciana Menezes. Legitimação institucional do jornalismo informativo nas mídias sociais digitais: estratégias emergentes no conteúdo de Zero Hora no Twitter. 2011. 189p. Dissertação (Mestrado em Comunicação) - Universidade Federal de Santa Maria, Santa Maria, 2011.

CARVALHO, Luciana Menezes. Contrato de informação do jornalismo no ecossistema midiatizado: estratégias semiolinguísticas da instância de produção no Facebook. 2015. 237p. Tese (Doutorado em Comunicação) - Universidade Federal de Santa Maria, Santa Maria, 2015.

CASAGRANDE, Magnos Cassiano. Encenação jornalística da violência no futebol: estudo de estratégias discursivas, efeitos de sentido e valores. 2014. 236p. Dissertação (Mestrado em Comunicação) - Universidade Federal de Santa Maria, Santa Maria, 2014.

CASAROLI, Lutiana. ZH em ZH: Valores agenciados na discursivização da cultura organizacional em "Cartas do Editor". 2009. 126p. Dissertação (Mestrado em Comunicação) Universidade Federal de Santa Maria, Santa Maria, 2009. 
FRANÇA. Vera. O objeto de pesquisa em comunicação: uma abordagem relacional. In: MOURA, Claudia Peixoto. LOPES, Maria Immacolata Vassallo de (org.). Pesquisa em comunicação: metodologias e práticas acadêmicas. Porto Alegre: EDIPUCRS, 2016.

FORBES. The World's Billionaires. Disponível em

<https://www.forbes.com/billionaires/list/>. Acesso em 12 de dezembro de 2019.

GROHMANN, Rafael. "A Comunicação Eletrônica é Epistemóloga": Entrevista com Muniz Sodré. Parágrafo, v. 3, n. 1, mar. 2015.p. 120-128. Disponível em:

http://revistaseletronicas.fiamfaam.br/index.php/recicofi/article/view/289/296. Acesso em: 04 nov. 2019.

GROSSMANN, Fabiane Volkmer. Estratégias comunicacionais de interfaces gráficas de webjornais: estudo do caso zero hora.com. 2008. 194p. Dissertação (Mestrado em Comunicação) - Universidade Federal de Santa Maria, Santa Maria, 2008.

HJARVARD, Stig. Midiatização: Teorizando a mídia como agente de mudança social e cultural. Matrizes. v.5, n.2, 2012.p. 53-91. DOI: 10.11606/issn.1982-8160.v5i2p53-91.

PÉRSIGO, Patrícia Milano. Pelas páginas de Zero Hora, o jornalismo público (des)coberto. 2015. 198p. Tese (Doutorado em Comunicação) - Universidade Federal de Santa Maria, Santa Maria, 2015.

SANTOS, M. Técnica, espaço e tempo: globalização e meio técnico-científico informacional. São Paulo: Hucitec, 1994.

TAVARES, Frederico de Mello Brandão. Entre objetos, objetos no entre: Revista, Jornalismo Especializado e Qualidade de vida. Revista Contemporânea, v. 6, n.2. dez. 2008.

UNIVERSIDADE FEDERAL DE SANTA MARIA. Área de Concentração. Poscom, 2019. Disponível em https://www.ufsm.br/cursos/pos-graduacao/santa-maria/poscom/area-deconcentracao/. Acesso em 12 dez. 2019.

UNIVERSIDADE FEDERAL DE SANTA MARIA. Mídia e Estratégias Comunicacionais. Poscom, 2019. Disponível em https://www.ufsm.br/cursos/pos-graduacao/santamaria/poscom/midias-e-estrategias-comunicacionais/. Acesso em 12 dez. 2019. 
Professora do Departamento de Comunicação e do Programa de Pós-Graduação em Comunicação da Universidade Federal de Santa Maria (UFSM), com pós-doutorado na Universidade Nacional de Quilmes/Argentina. Líder do Grupo de Pesquisa Comunicação Institucional e Organizacional/CNPq.

\section{Amanda Frick Martins}

Doutoranda em Comunicação, na linha de pesquisa Mídia e Estratégias Comunicacionais, do Programa de Pós-Graduação em Comunicação da UFSM.

Kauane Andressa Müller

Mestra em Comunicação pelo Programa de Pós-Graduação em Comunicação da UFSM.

Membro do Grupo de Pesquisa Comunicação Institucional e Organizacional/CNPq.

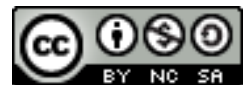

Esta obra está licenciada com uma Licença

Creative Commons Atribuição-NãoComercial-CompartilhaIgual 4.0 Internacional 